\title{
DEIMOGRAPHIC, SOCIOECONOIMIC AND CLINICAL PROFILE OF OCULAR CHEMICAL INJURIES IN TERTIARY CARE CENTRE IN CENTRAL INDIA
}

KEY WORDS: ocular chemical injury, ocular surface burns, clinical characteristics

\section{Dr. Shweta Walia}

\section{Dr Sapna} Sabnani*

\section{DrVijay Bhaisare}

Professor , Department of Ophthalmology Mahatma Gandhi Memorial Medical College M.Y.Hospital Indore (M.P.)

Resident, Department of Ophthalmology Mahatma Gandhi Memorial Medical College M.Y.Hospital Indore (M.P.).*Corresponding Author

Professor , Department of Ophthalmology Mahatma Gandhi Memorial Medical College M.Y.Hospital Indore (M.P.).

PURPOSE: To identify risk factors of Ocular chemical injuries by studying demographic, socio-economic and clinical characteristics of patients and suggest preventive measures. DESIGN: Prospective hospital-based study. PARTICIPANTS: Patients who presented to tertiary care hospital in central India with ocular chemical burns during February 2019-2020.METHODS: In this study a total of 41 patients (49 eyes) were included. Patient data recorded were Age, Gender, Occupation, Education, socio-economic status, location and mode of injury, type of chemical, use and awareness of Personal Protective Equipment (PPE) and first aid. Clinical characteristics studied were initial and final Best corrected visual acuity (BCVA), grade of injury, Intra- ocular pressure (IOP) at presentation, management and complications. The variables were evaluated for potential relationships with visual outcome. RESULTS: Average age was 32.05+15.1 years with Male:Female ratio of 1.9:1. Total of 13 patients (31.7\%) were illiterate, belonged to Upper Lower IV socio-economic class $(n=20,48.8 \%)$. Most were semi-skilled workers $(n=19,46.3 \%)$ and $61 \%$ of the total injuries occurred at workplace. Accidental mode of injury was more prevalent ( $\mathrm{n}=38,92.7 \%)$, most common causative chemical was alkali ( $n=27$ eyes, 55.1\%). Low grade burns (Grade 1,2 and 3) were most observed ( $n=34,69.38 \%$ ). Majority of eyes $(n=39,79.6 \%)$ were medically managed. Risk factors for poor final BCVA using multivariate logistic regression analysis was poor initial BCVA $(p=0.011)$ and grade of chemical injury $(p=0.007)$. Conclusion: Chemical injuries are commonly encountered by patients of low Socio-Economic Status (SES), who are mostly illiterate. Most sustained injury at workplace and were not using PPE. These findings identify need for awareness programs with audio-visual components that are easily understood. It also highlights need for safer workplace practices.

\section{INTRODUCTION}

Chemical injuries to the eye form a significant proportion of ocular traumas with incidence ranging from $11.5 \%$ to $22.1 \%$.

${ }^{[1,2]}$ It is a true ocular emergency and requires immediate intervention.

Ocular chemical injuries vary in severity, with the more severe end of the spectrum having drastic consequences on ocular surface and visual function outcomes as well as significant and extensive impact on vision related quality of life of patients ${ }^{[3]}$

Furthermore, chemical injuries to eye can result in significant economic burden to individuals, families, and countries due to the time lost at work, the need for family care giving, treatment and follow-up costs, visual rehabilitation, and ocular reconstructive surgery ${ }^{[4]}$ Early and appropriate intervention ensures the best possible outcome for this potentially blinding condition. It is therefore essential that the public, emergency teams and ophthalmologists are able to manage these patients effectively, with the latter having an added role of educating these other groups.

Epidemiological research into who suffers these injuries, how, where, and why they occur and the way they are treated can provide valuable data for future actions geared towards prevention planning and management, therefore this study was undertaken to know the clinical, demographic and socioeconomic profile of patients who suffered from chemical injuries so as to identify the risk groups and use this information to provide recommendations for future prevention of such events.

\section{SUBJECTS AND METHODS:}

The study included all the patients who presented with ocular chemical burns at a tertiary care centre in central India during February 2019-February 2020. The study was approved by an institutional review board and adhered to the tenets of the Declaration of Helsinki. Written informed consent was obtained. Data recorded was age, sex, educational |www.worldwidejournals.com qualification, occupation, socioeconomic status (modified Kuppuswamy scale) ${ }^{[5]}$, location and mode of chemical injury, awareness and use of personal protective equipment, awareness of first aid, intoxication status, laterality, type of chemical, grade of injury, Initial and final BCVA, IOP at time of presentation, management methods, and complications.

The patients in the study were managed depending upon the time of presentation and severity of ocular injury. Patients who presented in the immediate stage were given emergency management which included copious irrigation of the affected eye with normal saline, with special emphasis on double eversion of lids and removal of any particulate matter or debris. Complete ocular examination was performed which included BCVA (using Snellen chart) and slit lamp examination with fluorescein staining was done to measure epithelial defect and to record limbal ischemia and to note clock hours of involvement. The chemical injury was graded using Dua's classification. ${ }^{[6]}$. IOP was measured using noncontact tonometer (Reichert $₫ 7$ Auto Tonometer). The elevated IOP was defined as IOP $>21 \mathrm{mmHg}$ on two different occasions.

After the emergency management based on patient's requirement, they were administered the medical treatment which consisted of topical therapy-Prednisolone acetate 1\% Hourly for initial seven days, Broad spectrum antibiotic four times daily, Cycloplegic (Homatropine $2 \%$ three times daily), Lubricating drops - Carboxy Methyl Cellulose Sodium (Hourly) for 2-4 weeks. Additionally, they were also given oral vitamin C 1-2 g/ day in three divided doses and doxycycline $100 \mathrm{mg}$ twice a day for 2-3 weeks. Antiglaucoma therapy, that included timolol maleate $0.5 \%$ eye drops and oral acetazolamide, was administered, if required.

Sweeping fornices with glass rod coated with antibiotic ointment was done daily to prevent symblepharon formation. The treatment was modified according to the response and medications were subsequently tapered. For those patients 
who required surgical interventions, surgery was performed in the form of Amniotic membrane grafting (AMG), Symblepharon release, or keratoplasty. A detailed, informed consent was taken prior to the procedure. The primary surgical intervention and subsequent outcome in each case was noted.

Statistical analysis was performed using a statistical software package (SPSS Statistics for Windows, Version 22.0. IBM Corp, Armonk, NY). Demographics and patient characteristics were reported as the means and standard deviations or percentages in each group.

Variables including age, gender, socio economic status, reporting time interval, initial BCVA, type of chemical, mode of injury, grade, and complications, were entered into the multivariate logistic regression analysis for relationship with final visual acuity. All $\mathrm{p}$ values were statistically significant when less than 0.05 .

\section{RESULTS:}

A total of 41 patients with ocular chemical injury were seen during study period. Of the total patients, 8 patients ( $19.5 \%)$ had bilateral burns. The demographics of these subjects are shown in Table 1. The mean age at the time of injury was 32.05 \pm 15.1 years (range, $1-74$ years). The age distribution showed that the peak occurrence of ocular chemical injury occurred in the 20-to-40-year group ( $\mathrm{n}=26[63.41 \%])$. Male-to-female ratio was of 1.9:1. Among these patients, 13 [31.7\%] were illiterate followed by those who had only received primary schooling $(n=10,24.4 \%)$.The highest number of total patients $(n=20,48.8 \%)$ belonged to the upper lower IV SES class followed by lower middle III $(n=17,41.5 \%$.)

19 patients were semi-skilled workers (46.3\%) and the second most common group involved was housewives $(n=10$, $24.4 \%$ ). The most common ocular injury setting was workplace in 25 patients (61\%), followed by home in 16 patients $(39 \%)$.

\begin{tabular}{|c|c|c|}
\hline \multicolumn{3}{|c|}{$\begin{array}{l}\text { TABLE 1: DEMOGRAPHIC AND SOCIO ECONOMIC } \\
\text { PROFILE OF CHEMICAL INJURY PATIENTS }(\mathrm{N}=41)\end{array}$} \\
\hline \multicolumn{2}{|c|}{ PATIENT DETAILS } & $\begin{array}{l}\text { NO OF PATIENTS } \\
(\%)\end{array}$ \\
\hline \multirow[t]{5}{*}{ AGE GROUP } & $0-9$ years & $2(4.87 \%)$ \\
\hline & 10-19 years & $4(9.75 \%)$ \\
\hline & $20-40$ years & $26(63.41 \%)$ \\
\hline & \begin{tabular}{|l|}
$40-60$ years \\
\end{tabular} & $6(14.63 \%)$ \\
\hline & $>60$ years & $3(7.31 \%)$ \\
\hline \multirow[t]{2}{*}{ SEX } & Male & $27(65.9 \%)$ \\
\hline & female & $14(34.1 \%)$ \\
\hline \multirow[t]{5}{*}{ EDUCATION } & Illiterate & $13(31.7 \%)$ \\
\hline & Primary school & $10(24.4 \%)$ \\
\hline & Middle school & $8(19.5 \%)$ \\
\hline & High school & $5(12.2 \%)$ \\
\hline & Undergraduate and above & $5(12.2 \%)$ \\
\hline \multirow{5}{*}{$\begin{array}{l}\text { SOCIOECO } \\
\text { NOMIC } \\
\text { STATUS } \\
\text { (SES)* }\end{array}$} & Upper class(I) & $1(2.4 \%)$ \\
\hline & Upper middle class (II) & $1(2.4 \%)$ \\
\hline & Lower middle class (III) & $17(41.5 \%)$ \\
\hline & Upper lower class (IV) & $20(48.8 \%)$ \\
\hline & Lower class (V) & $2(4.9 \%)$ \\
\hline \multirow{5}{*}{$\begin{array}{l}\text { OCCUPATIO } \\
\mathrm{N}\end{array}$} & Unskilled & $5(12.2 \%)$ \\
\hline & \begin{tabular}{|l|} 
Semi-skilled \\
\end{tabular} & $19(46.3 \%)$ \\
\hline & \begin{tabular}{|l|} 
Skilled \\
\end{tabular} & $2(4.9 \%)$ \\
\hline & Student & $5(12.2 \%)$ \\
\hline & Housewife & $10(24.4 \%)$ \\
\hline \multirow[t]{2}{*}{ LOCATION } & Workplace & $25(61 \%)$ \\
\hline & Home & $16(39.0 \%)$ \\
\hline
\end{tabular}

Out of 25 patients who suffered chemical injury at workplace, only three were aware that the chemical they were using was hazardous and that the use of protective equipment was advised while using them. However, none of them used PPE. Most common mode of injury was accidental. ( $n=38,92.7 \%)$. Only 3 cases of assault were reported. (7.3\%). A variety of chemicals were involved in these injuries. However, the most common causative chemical was Alkali ( $n=27$ eyes, $55.1 \%$ ) followed by acid ( $n=16$ eyes, $32.7 \%$ ). 5 eyes suffered chemical injury from mixed or unknown chemical and one eye from organic compound. The presentation interval of the patients was recorded under two categories: within 24 hours and post 24 hours. Only 34 patients presented to the hospital within 24 hours of injury. In 49 eyes of 41 patients, the most common classification of the severity of ocular chemical injury was grade I in 14 eyes (28.6\%), followed closely by grade II in 12 eyes (25.5\%). (Figure 1)

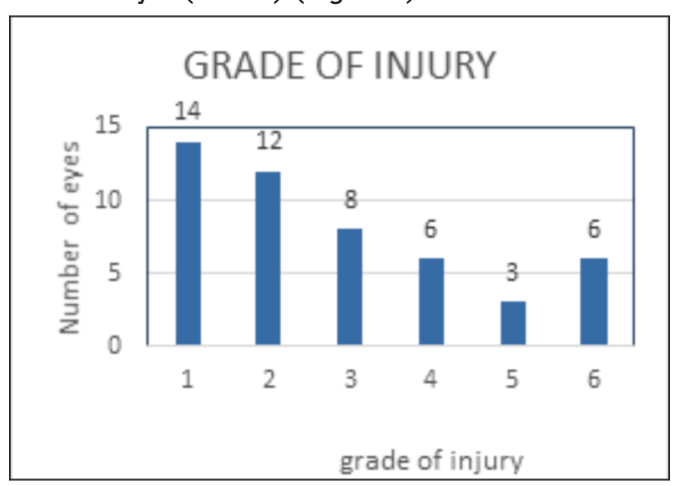

Figure 1: The number of eyes for grade of injury

Visual acuity at presentation ranged from $6 / 6$ to no perception of light. Among the 49 eyes of 41 patients, 19 (38.8\%) eyes had a visual acuity between 6/6-6/12 at the time of presentation, followed by $12(24.5 \%)$ eyes with a visual acuity between 6/18-6/36.

15 eyes (30.6\%) had elevation of IOP of more than $21 \mathrm{~mm} \mathrm{Hg}$ at the time of presentation and required IOP lowering treatment. Majority of eyes ( $n=39,79.6 \%)$ were medically managed. Surgical intervention was performed in 10 eyes $(20.4 \%)$ in the form of AMG ( $n=7)$, symblepharon release $(n=2)$ and keratoplasty $(n=1)$. Patients who underwent symblepharon release presented late. At the time of final follow up one month from the day of presentation; 34 eyes $(69.4 \%)$ reported visual acuity between $6 / 6-6 / 12$. The most common complication seen was elevated IOP ( $n=15$ eyes, $30.61 \%$ ) followed by corneal opacity in 8 eyes (16.32\%). Some patients suffered from more than 2 complications. Risk factors for the poor final BCVA Using Multivariate logistic regression analysis was poor initial BCVA $(p=0.011)$ and grade of chemical injury ( $p$ $=0.007)$. (Table 2$)$.

Table 2: Multiple logistic regression analysis for potential factors associated with final BCVA

\begin{tabular}{|l|l|l|}
\hline PARAMETER & Coefficients & P VALUE \\
\hline AGE & 0.003 & 0.916 \\
\hline GENDER & -0.104 & 0.317 \\
\hline EDUCATION & 0.018 & 0.859 \\
\hline OCCUPATION & -0.010 & 0.317 \\
\hline SOCIO ECONOMIC STATUS & 0.006 & 0.894 \\
\hline MODE OF INJURY & -0.171 & 0.061 \\
\hline REPORTING TIME INTERVAL & -0.029 & 0.088 \\
\hline TYPE OF CHEMICAL & 0.045 & 0.50 \\
\hline GRADE OF INJURY & 0.249 & 0.007 \\
\hline INITIAL BCVA & -0.029 & 0.011 \\
\hline BCVA: best corrected visual acuity \\
\hline
\end{tabular}

\section{DISCUSSION:}

The present study described the outcome of 41 patients of chemical injury seen over one year period. In the study the mean age of the patients was 32.05 years. These findings are 
comparable to the retrospective case series conducted by Hong et al in $2010^{[7]}$ in Shanghai where the age distribution of the victims was $35.3 \pm 14.8$ years. In our study, $65.9 \%$ patients were males of which $55.5 \%$ belonged to the age group of working adults. This result is in accordance with epidemiological data from a study conducted by Macdonald et al in $2009^{[8]}$ This implies that ocular chemical injuries might create an economic burden on the patient and their families in addition to the visual impairment. The increased incidence in males can also be attributed to the fact that they have high occupational exposure for chemical eye injuries. Semiskilled workers (mechanics, painters, factory worker) formed $46.3 \%$ of the total patients. This result is mirrored by the study conducted by Saini et al in $1993^{[9]}$, in which he found that majority of the victims were those working in factories and laboratories (64\%). Most injuries in our study occurred at workplace $(61 \%)$ which is the finding supported by several studies. ${ }^{[7,8,9]}$ Among injuries at workplace, only 3 patients were aware about the need of personal protective glasses at time of handling those chemicals, however, none of them were using any.

This finding is comparable to the study conducted by Adepoju et al in $\mathbf{2 0 0 7}^{[10]}$ who reported that among the 13 out 17 accidental cases that occurred at workplace, none of the victim had protective eyeglasses on at the time of the accident. An interesting point regarding this finding was made by Hong et al in $2010^{[7]}$ which reported that none of the 190 patients who suffered ocular chemical injuries wore any kind of eye protection at the time of injury even though they believed that such protection was required. These findings show the poor safety awareness and practice among workers and highlight the importance of formally educating them about the use of PPE and where necessary the legislative authorities make it compulsory for employers to provide their workers with such facilities while ensuring compliance of the same.

In the present study, $48.8 \%$ of the patients $(n=20)$ belonged to Upper Lower IV group on the modified Kuppuswamy scale of socio-economic status. SES is one of the important factors affecting the health condition of an individual or a family. SES influences the acceptability, affordability, accessibility, and actual on-ground utilisation of various available health facilities. Higher SES indicates a better access to healthcare ${ }^{[5]}$ Since majority of patients in our study belonged to a lower SES, it can be conjectured that the incidence of the chemical eye injury, in addition to being a health problem, was also a major economic burden thereby creating more hurdles for people who already face challenges in accessing healthcare. Among the 41 patients in the study, 13 patients (31.7\%) were illiterate. Since this result suggests that patients falling into these groups might not be able to read or write, it is required that the warnings and safety protocols mandated at the workplace and on the chemical product packaging should have easy-to-understand pictorial representation. Awareness programs conducted in vernacular languages at regular time intervals would also help to bridge the gaps in information and understanding. $87.8 \%$ patients were unaware about the first aid in case of ocular chemical injuries. A study by Hong et al in $2010^{[7]}$ reported similar findings where patients in their study lacked education and awareness about the correct method of handling chemicals and especially first aid measures.

This result suggests that the public might not be aware about what is the first aid procedure in the event of an ocular chemical injury. Therefore, first aid awareness programs must be conducted, followed by exit surveys to assess their impact. This would help us identify the gaps in knowledge and address them with more rigour in future. Most injuries $(n=38$, $92.7 \%$ ) were accidental in nature. These findings are in accordance with study done by Saini et al in $1993^{\left[{ }^{[9]}\right.}$ where $93.1 \%$ of the cases were accidental.
It is generally known that cases of assault tend to be more severe in terms of ocular tissue damage and visual loss as shown in studies carried out by Adepoju et al(2007) ${ }^{[10]}$ and Ukponmwan CU (2000) ${ }^{[1]}$ Alkali based injuries were the highest among the 49 eyes who suffered chemical injury (55.1\%), followed by acid (32.7\%).

Alkali agents are reported to be the most common cause of ocular chemical injuries in the study conducted by macdonald et al (2009) ${ }^{[8]}$ and Hong et al (2010) ${ }^{[7]}$ Haring et al $^{[4]}$ also reported that among injuries that were classified as either alkalic or acidic, children three years or younger had more alkali burns than men aged between 18 and 64 years. This finding matches with our study that two patients belonging to the paediatric age group also suffered injury from alkaline agent (lime). Since chuna injuries are more common in paediatric age group, parental guidance becomes important in prevention of such injuries. Government policies should also mandate the sale of chuna in packets that have more secure packaging and would not burst easily. The chemical injuries in our study were graded using Dua classification. Low grade chemical injuries (Grade 1 and 2) were more common (53.1\%).

The findings of our study match with the study conducted by Li et al (2020) ${ }^{[12]}$ where the most common classification was grade 2 and grade 1 Roper Hall chemical injury, indicating that bulk of chemical injuries were mild to moderate. Two out of 3 cases of assault related injury in our study were grade 6 and bilateral. Patients in our study who suffered assault related injuries suffered from a higher grade of ocular burn as opposed to accidental cases where the grades were relatively low. This is in accordance with the studies that report that assault related ocular chemical injuries are usually of higher grade.$^{[9]}$ Also, notably, the 2 patients of paediatric age group in our study also suffered severe grade 6 unilateral injury. It has been found that severe chemical injuries are more common in children. In a study done by Vajpayee et al (2014) ${ }^{[13]}$ on ocular chemical injuries in paediatric age group it was found that a large proportion of patients $(70.1 \%)$ had severe ocular burns (grade 3 and grade 4 Roper Hall).

Among the 49 eyes of 41 patients, majority of patients ( $n=19$, $38.8 \%$ ) had visual acuity between $6 / 6-6 / 12$ at the time of presentation. In our study majority of eyes ( $n=39,79.6 \%)$ were medically managed. When compared to visual acuity at presentation there was a definite improvement of visual acuity at final follow up. Severe impairment of best corrected visual acuity was seen in $22.5 \%$ of patients who had vision ranging from $6 / 60$ to No PL. However, in our study, eyes sustaining grade 5 and 6 injuries suffered from poor visual outcome at final follow up. In our study the risk factors for the poor final best corrected visual acuity using multivariate regression analysis were poor initial BCVA $(p=0.011)$ and grade of chemical injury $(p=0.007)$.

The degree of severity of injury at initial presentation largely determines the final visual prognosis and several studies have emphasised poor visual outcome following severe ocular burns ${ }^{[14]}$

\section{CONCLUSION}

Ocular chemical injury involves younger demographics therefore has significant socio-economic impact. Majority of patients who suffer from chemical injury are illiterate or have done primary schooling, therefore awareness programme should be made more audio- visual and in vernacular language. Regular checks should be made to ensure that workers are properly trained in use of chemicals, as most common location of injury is workplace. Most of the injuries by chemicals are mild grade and can be managed medically. Severe injuries are more common in cases of assault.

\section{LIMITATION OF STUDY}

Since the study was conducted over a short time period of 
twelve months and at a tertiary centre, some selection bias might have occurred. Larger epidemiological studies may provide better insights due to a larger sample size. The study was unable to access the economic effect of the injury in monetary terms such as the lost workdays, loss of productivity and cost of medical care that the patient might have incurred; if available, this data can possibly give a clearer picture of the economic burden faced by a patient.

\section{REFERENCES:}

1. Wagoner MD. Chemical injuries of the eye: Current concepts in pathophysiology and therapy. Surv Ophthalmol 1997;41(4):275-313.

2. Sharma N, Kaur M, Agarwal T, Sangwan VS, Vajpayee RB. Treatment of acute ocular chemical burns. Surv Ophthalmol 2018;63(2):214-35.

3. Le Q, Chen Y,Wang X, LiY, Hong J, Xu J.Vision-related quality of life in patients with ocular chemical burns. Invest OphthalmolVis Sci 201 1;52 (12):8951

4. Haring RS, Sheffield ID, Channa R, Canner JK, Schneider EB. Epidemiologic trends of chemical ocular burns in the United States. JAMA Ophthalmol 2016;134(10):1119-24.

5. Wani RT. Socioeconomic status scales-modified Kuppuswamy and Udai Pareekh's scale updated for 2019.J Fam Med Prim care 2019;8(6):1846-9.

6. Dua HS, King AJ, Joseph A. A new classification of ocular surface burns. Br J Ophthalmol 2001;85(11):1379-83.

7. Hong J, Qiu T,Wei A, Sun X, Xu J. Clinical characteristics and visual outcome of severe ocular chemical injuries in shanghai. Ophthalmology 2010;117(12):2268-72.

8. Macdonald ECA, Cauchi PA, Azuara-Blanco A, Foot B. Surveillance of severe chemical corneal injuries in the UK. Br J Ophthalmol 2009;93(9):1177-80.

9. Saini JS, Sharma A. Ocular chemical burns--clinical and demographic profile. Burns 1993;19(1):67-9.

10. Adepoju F, Adeboye A, Adigun I. Chemical eye injuries: Presentation and management difficulties. Ann Afr Med 2007;6(1):7-11.

11. Ukponmwan CU. Chemical injuries to the eye in Benin City, Nigeria. West Afr J Med 2000;19(1):71-6.

12. Li T, Jiang B, Zhou X. Clinical characteristics of patients hospitalized for ocular chemical injuries in Shanghai from 2012 to 2017. Int Ophthalmol 2020; 40(4):909-16.

13. Vajpayee RB, Shekhar H, Sharma N, Jhanji V. Demographic and clinical profile of ocular chemical injuries in the pediatric age group. Ophthalmology 2014;121(1):377-80.

14. Pfister RR. The effects of chemical injury on the ocular surface. Ophthalmology 1983;90(6):601-9. 